\title{
PROYEKSI KEBUTUHAN ENERGI LISTRIK PROVINSI DKI JAKARTA PADA TAHUN 2016 - 2025 DENGAN MENGGUNAKAN METODE SIMPLE ECONOMETRIC
}

\author{
Muhammad Hadyan Raif ${ }^{*}$, Karnoto, and Agung Nugroho \\ Departemen Teknik Elektro, Universitas Diponegoro \\ Jl. Prof. Sudharto, SH, Kampus UNDIP Tembalang, Semarang 50275, Indonesia \\ ${ }^{*}$ E-mail : ififraif@gmail.com
}

\begin{abstract}
Abstrak
Ketersediaan energi listrik merupakan aspek yang sangat penting dan bahkan menjadi suatu parameter untuk mendukung keberhasilan pembangunan suatu daerah. Ketersediaan energi listrik yang memadai dan tepat sasaran akan memacu perkembangan pembangunan daerah seperti sektor industri, komersial, pelayanan publik dan bahkan kualitas hidup masyarakat dengan semakin banyaknya warga yang menikmati energi listrik. Pembuatan perencanaan proyeksi tugas akhir ini penulis menggunakan software SEEx (Simple Econometric Extended) dimana terintergrasi dengan Microsoft Excel 2000 - 2007. Pembuatan perencanaan dilakukan pada wilayah Provinsi DKI Jakarta tahun 2016 - 2025 dengan penyelesaian persamaan menggunakan exponensial dan pengembangan model DKL 3.2. Variabel bebas yang digunakan meliputi PDRB, Harga listrik dan jumlah pelanggan. Proyeksi ini menganalisis mengenai perhitungan tambahan daya, selisih error antara hasil proyeksi energi listrik terhadap dokumen RUPTL dengan metode MAPE, serta analisis tambahan mengenai drop tegangan kondisi jaringan per feeder masing - masing dan uprating transformator GI Jatirangon saat kondisi eksisting dengan ETAP 12.6.0. Sedangkan simulasi tambahan mengenai voltage drop GI Jatirangon yang mengacu pada RUPTL menggunakan software ETAP 12.6.0 sudah sesuai standard yang telah ditetapkan oleh PLN yaitu di bawah $5 \%$.
\end{abstract}

Kata Kunci : Kebutuhan energi listrik, Proyeksi, Simple Econometric, RUPTL, ETAP 12.6.0, Drop tegangan

\begin{abstract}
Availability of electrical energy is a very important aspect and even becomes a parameter to support the successful development of a region. The availability of sufficient and well-used electrical energy will accelerate regional development such as industrial, commercial, public services and also the quality of life indicatedly and it is indicated by increasing number of people who uses electricity. This final projection planning is using SEEx software (Simple Econometric Extended) which is integrated with Microsoft Excel 2000 - 2007. Planning is d'one in the area of DKI Jakarta Province in 2016 - 2025 with completion of exponential equation and DKL 3.2 model development. The independent variables used include PDRB, electricity price and number of customers. This projection analyzes the calculation of additional power, the difference in error between the projected electrical energy of the RUPTL document and the MAPE method, and performs additional analysis of the network voltage drops per feeder and upright transformer of Jatirangon GI during the existing condition with ETAP 12.6.0. While the additional simulation of GI Jatirangon voltage drop that refers to RUPTL using ETAP 12.6.0 software is in accordance with the standard set by PLN that is under 5\%.
\end{abstract}

Keywords: Demand of Electrical Energy, Forecast, Simple Econometric, RUPTL, ETAP 12.6.0, Voltage Drop

\section{Pendahuluan}

Ketersediaan energi listrik merupakan aspek yang sangat penting dan bahkan menjadi suatu parameter untuk mendukung keberhasilan pembangunan suatu daerah[1]. Ketersediaan energi listrik yang memadai dan tepat sasaran akan memacu perkembangan pembangunan daerah seperti sektor industri, komersial, pelayanan publik dan bahkan kualitas hidup masyarakat dengan semakin banyaknya warga yang menikmati energi listrik[1]. Kemudian secara langsung maupun tidak langsung, hal itu akan mempengaruhi pertumbuhan ekonomi dan tingkat kesejahteraan masyakarat[1].

Pertumbuhan ekonomi merupakan faktor yang mempengaruhi pertumbuhan energi listrik, selain dari faktor tersebut perkembangan energi listrik juga 
dipengaruhi oleh faktor perkembangan penduduk dalam pengertian jumlah pelanggan yang akan dialiri listrik [2].

Perencanaan ketenagalistrikan dalam lingkup nasional maupun daerah banyak menggunkan berbagai macam metode. Maka dalam tugas akhir ini menggunakan salah satu metode yaitu Simple Econometric[3]. Metode ini digunakan oleh PLN dalam penyusunan prakiraan kebutuhan listrik pada RUPTL yang telah teruji[4].

Adapun tujuan penelitian tugas akhir ini adalah dilakukan proyeksi kebutuhan energi listrik pada tahun 2016 hingga 2025 di Provinsi DKI Jakarta dengan menggunakan metode Simple Econometric. Proyeksi perencanaan yang dibahas adalah kosumsi energi, jumlah pelanggan energi listrik dan daya tersambung serta analisis tambahan mengenai drop tegangan kondisi jaringan per feeder masing - masing dan uprating transformator GI Jatirangon saat kondisi eksisting yang mengacu dengan RUPTL dengan ETAP 12.6.0.

\section{Metode}

\subsection{Flowchart Proyeksi Simple-E}

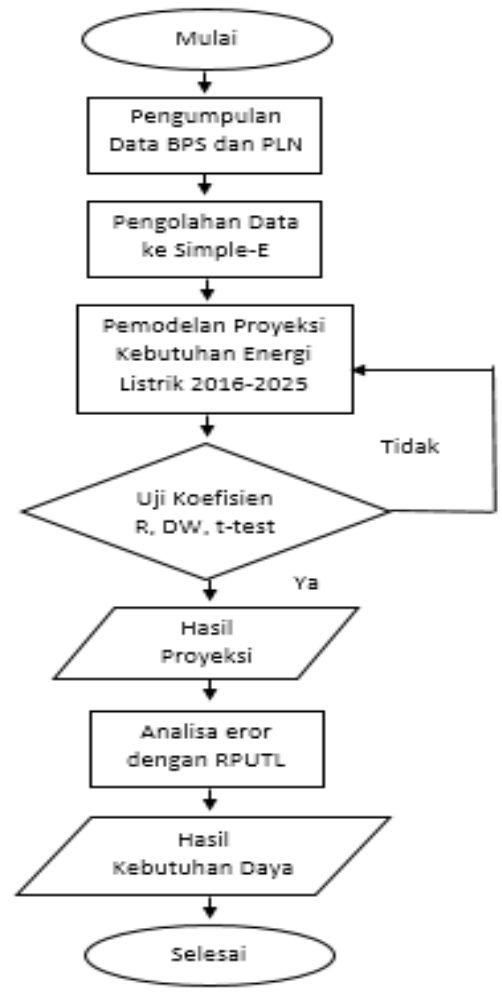

Gambar 1. Diagram Alir Proyeksi Energi listrik

\subsection{Model Peramalan Simple-E}

Simple Econometric menggunakan model OLS yaitu Ordinary Least Square, regresi linier dan non linier. Mengembangkan model DKL 3.2 dengan penambahan variabel harga listrik dan jumlah pelanggan. Berikut persamaan yang digunakan dalam perhitungan penelitian ini.
a) Rumah Tangga
JumlahPelanggan $=(P O P / R P R T) * E L E C$
Konsumsi listrik $=f(G D P, H N R E S, P L R E S)$
Daya tersambung $=f(P L R E S)$
Keterangan:
POP = Jumalah Penduduk
RPRT = Rata-rata penghuni rumah tangga
$R P R T=P O P / R T$
RT = Jumlah Rumah Tangga
ELEC = rasio Elektrfikasi
GDP $=$ PDB/PDRB total
HNRES = Harga Listrik Rumah Tangga
PLRES $=$ Pelanggan Rumah tangga
b) Komersil/bisnis
JumlahPelanggan $=(\mathrm{PLCOM}-1 *(1+\mathrm{GCOM}))$
Konsumsi listrik $=\mathrm{f}(\mathrm{GDPCOM}, \mathrm{PLCOM}$
Daya tersambung $=\mathrm{f}(\mathrm{PLCOM})$
Keterangan:
PLCOM-1=Pelanggan listrik sebelumnya
GCOM = Pertumbuhan PDRB komersil
GDPCOM =PDB/PDRB komersil
GDPCOM $=$ GDP* $($ PCM/PTL $)$
GDP $\quad=$ PDB/PDRB Total
PCM = Pertumbuhan Komersil/Bisnis
PTL = Pertumbuhan Total
PLCOM = Pelanggan komersil

c) Publik

Jumlah Pelanggan $=($ PLPUB $-1 *(1+$ GPUB $))$

Konsumsi listrik $=\mathrm{f}($ GDPPUB,PLPUB $)$

Daya tersambung=: $\mathrm{f}$ (PLPUB)

Keterangan:

PLPUB-1 = Pelanggan listrik sebelumnya

GPUB = Pertumbuhan PDRB publik

GDPPUB $=$ PDB/PDRB publik

GDPCOM $=$ GDP* $($ PPUB/PTL $)$

GDP $=$ PDB/PDRB Total

PPUB = Pertumbuhan Publik

PTL = Pertumbuhan Total

PLPUB = Pelanggan publik

d) Industri

Jumlah Pelanggan $=(P L I N D-1 *(1+G I N D))$

Konsumsi listrik $=f(G D P I N D, P L I N D)$

Daya tersambung $=f(P l I N D)$

Keterangan

PLIND-1 = Pelanggan listrik sebelumnya 
GPIND $=$ Pertumbuhan PDRB industri

GDPIND $=$ PDB/PDRB industri

$G D P C O M=G D P *(P I N D / P T L)$

GDP $\quad=$ PDB/PDRB Total

PIND = Pertumbuhan Industri

PTL = Pertumbuhan Total

PLIND = Pelanggan industri

Sementara rumus yang digunakan untuk memperhitungkan kebutuhan daya menggunakan rumus sebagai berikut.

a. Etingkat pertumbuhan $=$ $\frac{x \text { tahun sekarang }-x \text { tahun sebelumnya }}{x \text { tahun sebelumnya }}$

b. rata2 pertumbuhan $=$ $\underline{\text { Itingkat pertumbuhan pertahunan }}$

\subsection{Indikator Keberhasilan Simple-E}

Pengujian dalam hasil Simple Econometric menyebutkan bahwa dalam pegujian model Simple Econometric terdapat 3 parameter utama sebagai berikut.

a) $R$ squared (Goodness of Fit)

$R$ squared merupakan istilah statistik yang memberikan informasi tentang seberapa fit suatu model. Semakin medekati nilai 1 mengindikasikan bahwa garis regresi tersebut sesuai dengan data aslinya secara sempurna.

b) T-Value (Test of Significance)

Uji statistik yang digunakan untuk mengetahui ada atau tidaknya perbedaan yang signifikan dari dua buah mean sampel dari dua variabel yang di bandingkan.

- $|\mathrm{t}| \geq 2 \quad$ : mempengaruhi variabel dependen signifikan

- $2>|t| \geq 1 \quad$ : cukup berpengaruh pada variabel dependen

- $|\mathrm{t}|<1 \quad$ : tidak memberikan pengaruh pada

c) Durbin Watson Test

Pengujian statistik yang digunakan untuk mengetahui ada tidaknya autokorelasi pada nilai residual dari sebuah analisis regresi

- $\quad \mathrm{DW}=1<\mathrm{DW}<3$ : Tidak ada autokorelasi

- $\mathrm{DW} \leq 0$ atau $\mathrm{DW} \geq 4$ : Maka ada autokorelasi

\subsection{Ukuran Akurasi Peramalan}

Untuk mendapatkan hasil peramalan yang baik maka diperlukan perhitungan error. Metode perhitungan MAPE (mean Absolute Percentage Error) digunakan sebagai perhitungan error hasil proyeksi dengan RUPTL.

$$
\text { MAPE }=\left(\frac{100}{n}\right) \sum\left|\mathrm{A}-\frac{\mathrm{F}}{\mathrm{A}}\right|
$$

Keterangan

$\mathrm{A}=$ permintaan aktual pada periode $\mathrm{t}$

$\mathrm{F}=$ hasil peramalan (forecast) pada peridoe $\mathrm{t}$

$\mathrm{n}=$ Jumlah data

\subsection{SEEx(Simple Econometric Extended)}

SEEx (Simple Econometric Simulation System, Expanded) merupakan sistem simulasi terintegrasi yang dikembangkan dari econometric simulation tool. SEEx merupakan aplikasi Add-ins untuk Microsoft Excel 20002007.

Operasi grafis dan visual membuat SEEx menjadi mudah digunakan dan dipelajari. SEEx menyediakan beragam pilihan estimasi seperti ordinary least File aplikasi SEEx merupakan sebuah Excel workbook dimana di dalam file tersebut terdapat tiga sheets yaitu Data Sheet, Model Sheet, dan Simulation square (OLS), auto-regression, dan nonlinear.

\subsection{Flowchart Simulasi Tambahan Dengan ETAP 12.6.0}

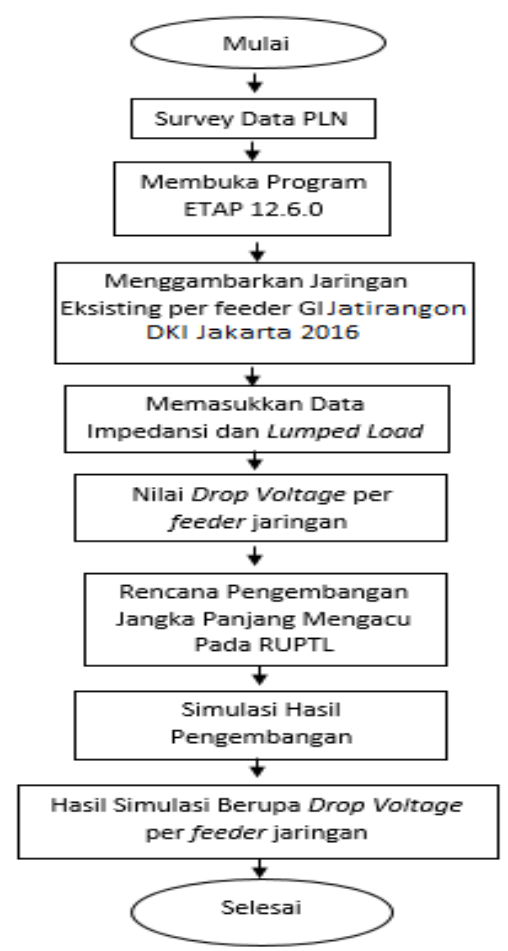

Gambar 2. Diagram Alir Simulasi ETAP 12.6.0

\section{Hasil dan Analisa}




\subsection{Proyeksi Kebutuhan Energi Listrik}

Proyeksi dari kebutuhan energi listrik Provinsi DKI Jakarta meliputi jumlah pelanggan energi listrik, daya tersambung serta kebutuhan energi listrik.

a) Jumlah Pelanggan Listrik

Berdasarkan rumus yang telah didapat maka hasi perhitungan sebagai berikut.

$$
\begin{aligned}
\text { Pelanggan } R T & =\left(4.736 .763 *\left(\frac{564.190 .161}{534.259 .593}\right)\right. \\
& =5.002 .128,39
\end{aligned}
$$

Tabel 1. Proyeksi Jumlah Pelanggan DKI Jakarta

\begin{tabular}{lccccc}
\hline Sektor & $\mathbf{2 0 1 6}$ & $\mathbf{2 0 1 7}$ & $\mathbf{2 0 1 8}$ & $\mathbf{2 0 1 9}$ & $\mathbf{2 0 2 0}$ \\
\hline RT/seribu & 5.002 .128 & 5.280 .851 & 5.573 .513 & 5.880 .712 & 6.203 .071 \\
Kom/seribu & 370.579 & 391.631 & 413.726 & 436.911 & 461.236 \\
Ind/seribu & 12.122 & 12.629 & 13.166 & 13.732 & 14.329 \\
Pub/seribu & 72.306 & 76.496 & 80.891 & 85.501 & 90.338 \\
TOT & $\mathbf{5 . 4 5 7 . 1 3 5}$ & $\mathbf{5 . 7 6 1 . 6 0 7}$ & $\mathbf{6 . 0 8 1 . 2 9 6}$ & $\mathbf{6 . 4 1 6 . 8 5 6}$ & $\mathbf{6 . 7 6 8 . 9 7 4}$ \\
\hline Sektor & $\mathbf{2 0 2 1}$ & $\mathbf{2 0 2 2}$ & $\mathbf{2 0 2 3}$ & $\mathbf{2 0 2 4}$ & $\mathbf{2 0 2 5}$ \\
\hline RT/seribu & 6.541 .229 & 6.895 .849 & 7.267 .614 & 7.657 .230 & 8.065 .424 \\
Kom/seribu & 486.751 & 513.505 & 541.553 & 570.949 & 601.748 \\
Ind/seribu & 14.956 & 15.614 & 16.304 & 17.026 & 17.783 \\
Pub/seribu & 95.410 & 100.729 & 106.304 & 112.148 & 118.271 \\
TOT & $\mathbf{7 . 1 3 8 . 3 4 6}$ & $\mathbf{7 . 5 2 5 . 6 9 7}$ & $\mathbf{7 . 9 3 1 . 7 7 5}$ & $\mathbf{8 . 3 5 7 . 3 5 3}$ & $\mathbf{8 . 8 0 3 . 2 2 6}$ \\
\hline
\end{tabular}

Berdasarkan tabel 1 diatas rata-rata pertumbuhan masingmasing sektor pemakai yaitu Rumah Tangga sebesar 4,5\%, Komersial sebesar 4,8\%, Publik sebesar $4,7 \%$, dan. Industri sebesar 3,9\%.

\section{b) Daya Tersambung}

Perhitungan menggunakan penyelesaian linier dengan variabel bebas menggunakan data pelanggan pada setiap sektor. Hasil proyeksi ini di lihat dari uji koefisien nya sebagi berikut.

$$
\text { daya tersambung }=a+b \text { PLRES }
$$

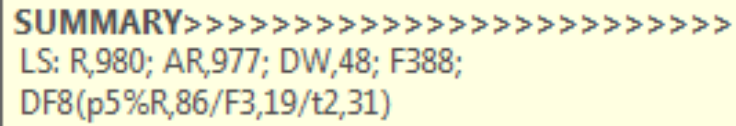

Gambar 3. Uji koefisien Proyeksi Daya Tersambung

Pada hasil diatas dapat dilihat bahwa hasil peramalan telah sesuai dengan hasil uji koefisien nya. Nilai dari $\mathrm{R}$ telah mendekati 1 , nilai DW terletak pada $1<\mathrm{x}<3$ berarti bahwa negatif autokorelasi pada nilai residual regresi sementara nilai t-test $\geq 2$ berarti bahwa variabel bebas memberikan pengaruh yang signifikan. Semua uji koefisien telah lolos dan didapatkan hasil sebagai berikut.

Tabel 2. Proyeksi Daya Tersambung DKI Jakarta (MVA)

\begin{tabular}{cccccc}
\hline Sektor & $\mathbf{2 0 1 6}$ & $\mathbf{2 0 1 7}$ & $\mathbf{2 0 1 8}$ & $\mathbf{2 0 1 9}$ & $\mathbf{2 0 2 0}$ \\
\hline RT & 8.741 & 9.316 & 9.921 & 10.555 & 11.221 \\
Kom & 8.082 & 8.696 & 9.341 & 10.017 & 10.727 \\
Ind & 5.123 & 5.741 & 6.395 & 7.084 & 7.812 \\
Pub & 1.951 & 2.107 & 2.270 & 2.441 & 2.621 \\
TOT & $\mathbf{2 3 . 8 9 7}$ & $\mathbf{2 5 . 8 6 0}$ & $\mathbf{2 7 . 9 2 6}$ & $\mathbf{3 0 . 0 9 7}$ & $\mathbf{3 2 . 3 8 0}$ \\
\hline Sektor & $\mathbf{2 0 2 1}$ & $\mathbf{2 0 2 2}$ & $\mathbf{2 0 2 3}$ & $\mathbf{2 0 2 4}$ & $\mathbf{2 0 2 5}$ \\
\hline RT & 11.919 & 12.651 & 13.419 & 14.223 & 15.066 \\
Kom & 11.471 & 12.251 & 13.070 & 13.927 & 14.826 \\
Ind & 8.575 & 9.377 & 10.217 & 11.097 & 12.019 \\
Pub & 2.809 & 3.007 & 3.214 & 3.431 & 3.658 \\
TOT & $\mathbf{3 4 . 7 7 4}$ & $\mathbf{3 7 . 2 8 6}$ & $\mathbf{3 9 . 9 2 0}$ & $\mathbf{4 2 . 6 7 8}$ & $\mathbf{4 5 . 5 6 9}$ \\
\hline
\end{tabular}

Dari tabel 2 diatas rata-rata pertumbuhan masing-masing sektor pemakai yaitu Rumah Tangga sebesar 6,24\%, Komersial sebesar 6,97\% dan Publik sebesar 9,95\%, 4 Industri sebesar 7,23\%.

c) Konsumsi Energi Listrik

Perhitungan menggunakan penyelesaian eksponensial dengan variabel bebas menggunakan data pelanggan pada setiap sektor. Hasil proyeksi ini di lihat dari uji koefisien nya sebagi berikut.

$$
\text { konsumsi }=a+b \ln G D P
$$

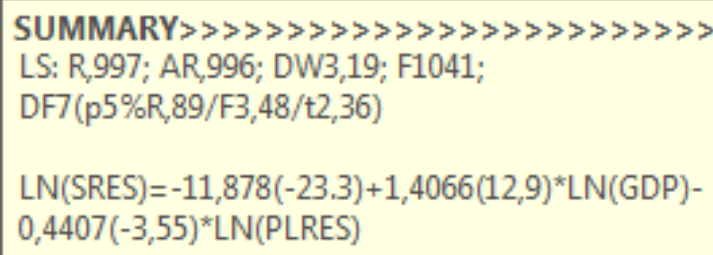

Gambar 4. Uji koefisisen kebutuhan energi listrik DKI Jakarta

Pada hasil diatas dapat dilihat bahwa hasil peramalan telah sesuai dengan hasil uji koefisien nya. Nilai dari $\mathrm{R}$ telah mendekati 1 , nilai DW tidak terletak pada $1<\mathrm{x}<3$ berarti bahwa positif autokorelasi pada nilai residual regresi sementara nilai t-test $\geq 2$ berarti bahwa variabel bebas memberikan pengaruh yang signifikan. Ketika tidak signifikan maka variabel akan disihkan sesuai dengan yang signifikan, hingga semua uji koefisien telah lolos dan didapatkan hasil sebagai berikut.

Dari tabel 3 diatas bahwa rata-rata pertumbuhan masingmasing sektor pemakai yaitu Rumah Tangga sebesar 5,3\%, Komersial sebesar 5,2\% dan Umum sebesar 6,3\%, Industri sebesar $14,4 \%$. 
Tabel 3. Proyeksi Konsumsi Listrik DKI Jakarta

\begin{tabular}{cccccc}
\hline Sektor & $\mathbf{2 0 1 6}$ & $\mathbf{2 0 1 7}$ & $\mathbf{2 0 1 8}$ & $\mathbf{2 0 1 9}$ & $\mathbf{2 0 2 0}$ \\
\hline RT & 15.808 & 16.658 & 17.549 & 18.482 & 19.460 \\
Kom & 14.005 & 14.736 & 15.501 & 16.300 & 17.135 \\
Ind & 3.302 & 3.511 & 3.731 & 3.964 & 4.209 \\
Pub & 12.932 & 14.761 & 16.883 & 19.340 & 22.182 \\
TOT & 46.048 & 49.668 & 53.666 & 58.088 & 62.988 \\
\hline Sektor & $\mathbf{2 0 2 1}$ & $\mathbf{2 0 2 2}$ & $\mathbf{2 0 2 3}$ & $\mathbf{2 0 2 4}$ & $\mathbf{2 0 2 5}$ \\
\hline RT & 20.484 & 21.555 & 22.677 & 23.850 & 25.077 \\
Kom & 18.007 & 18.918 & 19.868 & 20.860 & 21.895 \\
Ind & 4.467 & 4.739 & 5.025 & 5.327 & 5.645 \\
Pub & 25.468 & 29.262 & 33.642 & 38.694 & 44.518 \\
TOT & $\mathbf{6 8 . 4 2 7}$ & $\mathbf{7 4 . 4 7 5}$ & $\mathbf{8 1 . 2 1 4}$ & $\mathbf{8 8 . 7 3 3}$ & $\mathbf{9 7 . 1 3 7}$ \\
\hline
\end{tabular}

d) Akurasi peramalan

Pada perhitungan ini membandingkan hasil proyeksi konsumsi listrik dengan proyeksi RUPTL. Perbandingan dilakukan karena pada RUPTL menggunakan data proyeksi yang berbeda sehingga digunakan sebagai dokumen pembanding.

Tabel 4. Perbandingan hasil proyeksi dengan RUPTL

\begin{tabular}{ccc}
\hline Tahun & RUPTL $(\mathrm{GWh})$ & Proyeksi $(\mathrm{GWh})$ \\
\hline 2016 & 46.481 & 46.057 \\
2017 & 50.214 & 49.677 \\
2018 & 53.820 & 53.676 \\
2019 & 57.738 & 58.098 \\
2020 & 61.735 & 62.999 \\
2021 & 65.396 & 68.439 \\
2022 & 69.870 & 74.488 \\
2023 & 74.551 & 81.228 \\
2024 & 79.426 & 79.426 \\
2025 & 84.838 & 84.838 \\
\hline
\end{tabular}

Hasil proyeksi kebutuhan energi listrik yang didapat kan kemudian dibandingan kan dengan data aktual pada tahun 2016. Perbandingan ini dilakukan untuk mencari nilai error dari hasil proyeksi sebagai validasi hasil proyeksi. Perbedaan data ini dapat dijadikan acuhan perbandingan pada hasil yang didapatkan.

Hasil perbandingan proyeksi dapat di dihitung nilai error nya berdasarkan perbandingan proyeksi dengan data aktual 2016. Perhitungan menggunakan persamaan sebagi berikut.

$$
\begin{aligned}
\operatorname{MAPE}(2016) & =\left(\frac{100}{1}\right) \sum\left|\frac{46.481-46.057}{46.481}\right| \\
& =0,91 \%
\end{aligned}
$$

Melihat hasil error diatas maka dapat di analisis bahwa hasil proyeksi dikatakan layak dengan nilai error sebesar $0,91 \%$.

Sehingga didapatkan tabil hasil perhitungan error dengan dokumen RUPTL sebagai berikut.

Tabel 5. Perhitungan error proyeksi dan RUPTL

\begin{tabular}{ccc}
\hline No. & Tahun & Error (\%) \\
\hline 1 & 2016 & 0,912 \\
2 & 2017 & 1,06 \\
3 & 2018 & 0,268 \\
4 & 2019 & 0,624 \\
5 & 2020 & 2,047 \\
6 & 2021 & 4,653 \\
7 & 2022 & 6,609 \\
8 & 2023 & 8,956 \\
9 & 2024 & 11,737 \\
10 & 2025 & 14,516 \\
\hline
\end{tabular}

Perbandingan proyeksi kebutuhan listrik Provinsi DKI Jakarta menggunakan Simple Econometric dengan dokumen RUPTL adalah berikut

\section{PERBANDINGAN PROYEKSI DAN RUPTL}

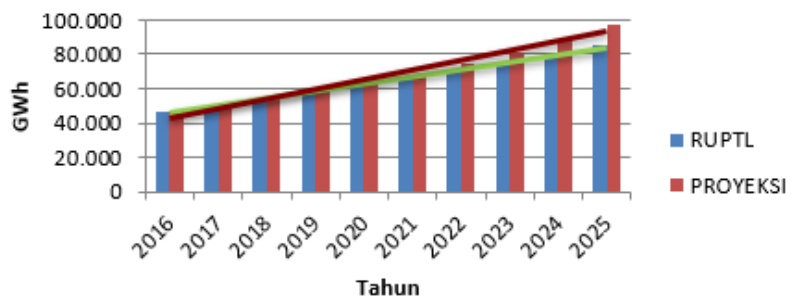

Gambar 5. Perbandingan proyeksi dengan dokumen RUPTL

\section{Kesimpulan}

Hasil proyeksi jumlah pelanggan, daya tersambung dan konsumsi energi listrik di Provinsi DKI Jakarta semakin meningkat setiap tahun nya, proyeksi jumlah pelanggan meningkat sebesar 5,46\%, kebutuhan energi listrik meningkat sebesar $8,1 \%$, dan daya tersambung meningkat sebesar 7,44\%. Untuk proyeksi jumlah total pelanggan Provinsi DKI Jakarta dari tahun 2016 sampai 2025 berturut-turut adalah 5.457.135, 5.761.607, 6.081.296, 6.416.856, 6.768.974, 7.138.346, 7.525.697, 7.931.775, $8.357 .353,8.803 .226$ pelanggan. Selanjutnya proyeksi total daya tersambung Provinsi DKI Jakarta dari tahun 2016 sampai 2025 berturut-turut adalah 23.897, 25.860, 27.926, 30.097, 32.380, 34.774, 37.286, 39.920, 42.678, 45.569 MVA. Dan proyeksi konsumsi listrik Provinsi DKI Jakarta dari tahun 2016 sampai 2025 berturut-turut adalah 46.048, 49.668, 53.666, 58.088, 62.988, 68.427, 74.475, 81.214, 88.733, dan 97.137 GWh.

\section{Referensi}


[1]. R. Wadyomukti, “Analisis Perbandingan Metode DKL 3.2 dengan Metode Simple Econometric," Universitas Gadjah Mada, Yogyakarta, 2010.

[2]. D. Marsudi, "Operasi Sistem Tenaga Listrik," Balai Penerbit \& Humas ISTN, Jakarta, 1990.

[3]. C.W Andro. "Analisis Proyeksi Kebutuhan Energi Listrik Dengan Menggunakan Motede Simple Econometric," Universitas Diponegoro, Semarang, 2015.

[4]. Rencana Umum Perencanaan Tenaga Listrik 2016-2025, PT PLN (Persero), 2016.

[5]. B. Kermanshahi dan H. Iwamiya, "Up to year 2020 load forecasting using neural nets," Enviromental Energy Engineering Tokyo University, 2002.

[6]. Nugroho, A. 2009. Sistem Infotmasi Prakiraan Kebutuhan Tenaga Listrik Sistem Distribusi Tenaga Listrik. Semarang: Teknik Elektro Fakultas Teknik UNDIP

[7]. D. Rachmawati dan B. Sutijo, "Pemodelan konsumsi listrik berdasarkan jumlah pelanggan PLN jawa Timur untuk kategori rumah tangga," Surabaya, 2013.

[8]. D. Suswanto. "Analisis Peramalan Beban dan Kebutuhan Energi Listrik," dalam Sistem Distribusi Tenaga Listrik.Univesitas Padang, 2009.

[9]. Data Statistik Tahun 2006-2015, PT. PLN (Persero) Distribusi DKI Jakarta.

[10]. A. Teguh, "Analisa Kebutuhan Gardu Induk Baru Di Wilayah APJ Pekalongan Dari Tahun 2012-2016," Universitas Diponegoro, Semarang, 2012

[11]. BPS DKI Jakarta, "DKI Jakarta Dalam Angka 20062015” Badan Pusat Statistik Indonesia (BPS) 